\title{
A Case of Laryngeal Fracture Precipitated by Swallowing
}

\author{
Edward Balai ${ }^{1}$, Navdeep Bhamra ${ }^{1}$, Keshav K. Gupta ${ }^{1}$, Karan Jolly ${ }^{1}$, James Barraclough ${ }^{1}$ \\ 1. Department of Otolaryngology, The Royal Wolverhampton NHS Trust, Birmingham, GBR
}

Corresponding author: Edward Balai, edbalai@gmail.com

\begin{abstract}
We report the case of a non-traumatic laryngeal fracture precipitated by swallowing where the symptoms were initially misinterpreted as representing a possible laryngeal malignancy. By the time of diagnosis, the injury was associated with an anterior neck abscess that required urgent surgical intervention. A 61-yearold male presented with dysphonia, odynophagia and neck swelling that had begun shortly after feeling a sudden crack in his neck upon swallowing. This was initially suspected to represent a laryngeal malignancy until, while awaiting outpatient investigation, the patient re-presented with rapid progression of his symptoms. Urgent CT scan revealed a vertical fracture of the thyroid cartilage, and a large anterior neck abscess causing posterior displacement. This required urgent surgical drainage. No underlying neoplasm was found, and the patient made a full recovery with complete resolution of symptoms. Non-traumatic laryngeal fractures are extremely rare. This case demonstrates the diagnostic challenge they can pose and is the first to describe the presentation and surgical management of a case with fracture displacement due to localised infection.
\end{abstract}

Categories: Otolaryngology

Keywords: non-traumatic laryngeal fracture, otolaryngology, cartilage fracture

\section{Introduction}

Laryngeal fractures are uncommon, with an estimated incidence of 1 in 30,000 patients presenting to hospital [1]. However, it can be a potentially life-threatening injury and therefore requires early diagnosis and management. The majority of cases occur as a consequence of high-energy direct trauma to the neck. Non-traumatic laryngeal fractures are very rare. A total of only seven cases have been reported in the literature, with sneezing, coughing and swallowing described as the precipitating events [2-7]. While blunt trauma to the neck would prompt active and thorough assessment for a laryngeal fracture, clinicians may not be aware that this type of injury can also occur after a seemingly innocuous event. We report the case of a non-traumatic laryngeal fracture precipitated by swallowing, where the symptoms were initially mistaken to represent a possible laryngeal malignancy. By the time of diagnosis, the injury had been complicated by the development of an associated anterior neck abscess.

Received 08/18/2020

\section{Case Presentation}

A 61-year-old male, ex-smoker, with a history of type 1 diabetes, was referred by his general practitioner (GP) to the ear, nose and throat (ENT) department with odynophagia, dysphonia, dysphagia and anterior neck swelling. The symptoms began while he was eating a cracker and, upon swallowing, he felt a painful crack in the right side of his neck. By the following day, the patient had developed hoarseness and pain on swallowing. He attended his GP five days later after developing neck swelling. At this point, it was thought the symptoms may represent an infection or a possible underlying malignancy; the patient was prescribed a course of oral antibiotics and referred urgently to the head \& neck clinic. At subsequent review in clinic, the patient reported ongoing odynophagia, dysphonia and dysphagia. Examination noted some fullness of the anterior neck. Flexible nasendoscopy (FNE) showed pooling of saliva and swelling of the right supraglottis. The patient was otherwise systemically well and managing to maintain adequate oral intake despite his symptoms. An expedited outpatient CT scan of the neck was requested to investigate for possible laryngeal malignancy. While awaiting this investigation, the patient re-presented to his GP with rapidly progressing symptoms and was referred to the ENT on-call team for same-day review. The patient had worsening dysphagia, now only managing sips of water. The anterior neck swelling had increased significantly in size and was now indurated with a central area of fluctuance. He underwent urgent inpatient contrast-enhanced CT scan of the neck (Figures 1,2). 


\section{Cureus}

(a)

(b)



(c)

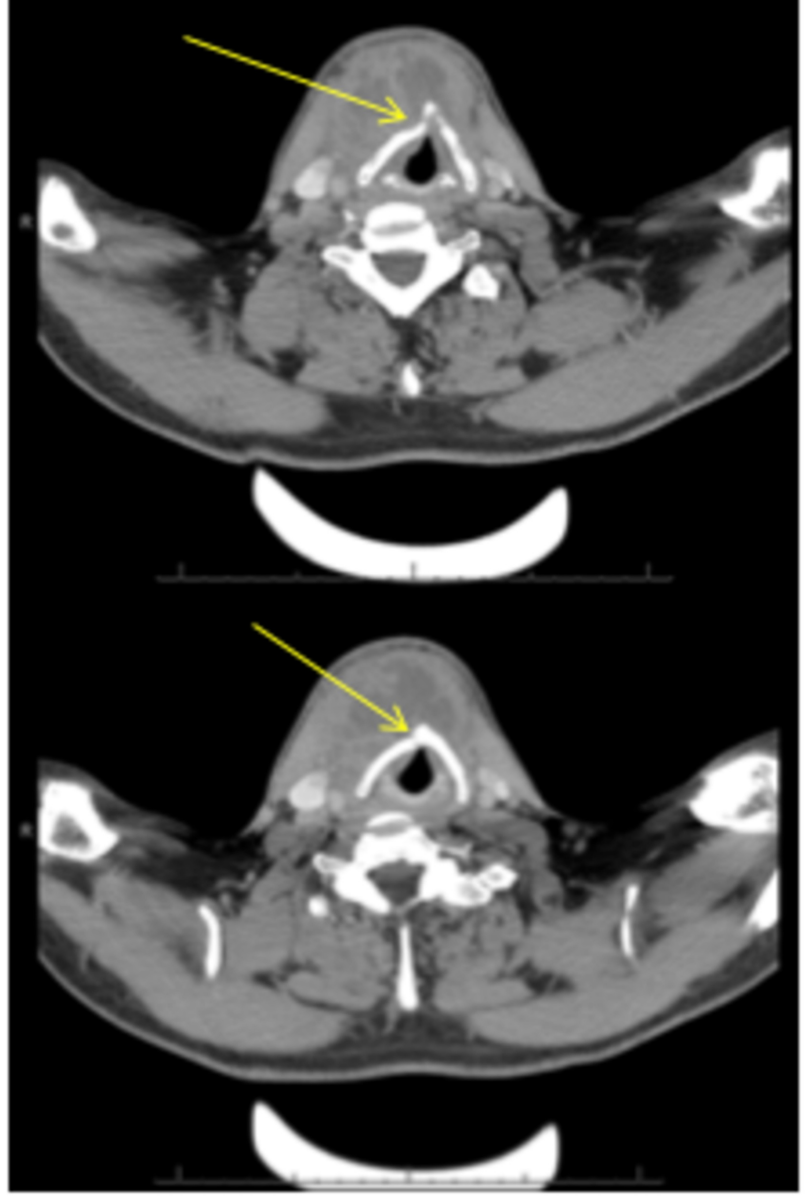

FIGURE 1: Axial sections (a-c) of contrast-enhanced CT scan

demonstrating a vertical fracture of the thyroid cartilage (red arrows), with depression of the right thyroid lamina posteriorly due to anterior neck collection. 


\section{Cureus}

(a)

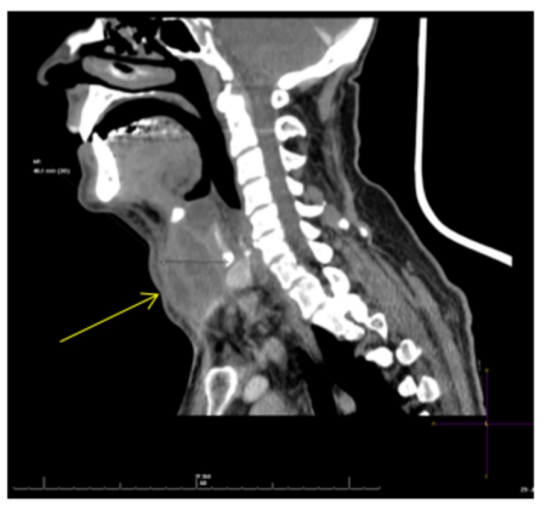

(b)



FIGURE 2: Sagittal (a) and coronal (b) sections of contrast-enhanced CT scan demonstrating a multiloculated collection (red arrows) in the midline of the anterior neck, measuring $7.5 \mathrm{~cm} \times 5.6 \mathrm{~cm} \times 4 \mathrm{~cm}$.

This demonstrated a vertical fracture of the thyroid cartilage to the right of the midline, with depression of the right thyroid lamina posteriorly causing mass effect on the trachea. There was also a large multiloculated collection in the midline just anterior to the thyroid cartilage. This extended superiorly up to the hyoid bone and inferiorly over the thyroid gland. The patient was commenced on intravenous antibiotics and underwent incision and drainage of the anterior neck collection. Through a lower transverse crease incision, $50 \mathrm{ml}$ of frank pus was drained from the cavity and a corrugated drain left in situ. At intubation, the anaesthetist noted the patient had started to develop supraglottic oedema, and he was therefore kept intubated and ventilated overnight on the intensive care unit. Regular intravenous dexamethasone (AAH Pharmaceuticals, London, United Kingdom) was initiated postoperatively. The patient was extubated on postoperative day 1 and started on a soft diet. However, on postoperative day 2 he reported some problems with swallowing. He was kept nil by mouth for a water-soluble contrast swallow, which showed no evidence of pharyngeal or oesophageal leak. Swallowing function subsequently improved with time. The drain was removed on day 3 , and the patient was discharged on postoperative day 7 to complete a short course of oral antibiotics. At one-month follow-up, there was no recurrence of symptoms. FNE examination was normal. Ultrasound of the neck confirmed complete resolution of the collection.

\section{Discussion}

Non-traumatic laryngeal fractures are exceedingly rare. Since the first reported case in 1950 [2] there have only been six other cases described (Table 1). 


\section{Cureus}

\begin{tabular}{|c|c|c|c|c|c|}
\hline Case & Demographic & $\begin{array}{l}\text { Precipitating } \\
\text { event }\end{array}$ & $\begin{array}{l}\text { Flexible nasendoscopy } \\
\text { findings }\end{array}$ & CT findings & Management \\
\hline $\begin{array}{l}\text { Quinlan } \\
\text { (1950) [2] }\end{array}$ & $\begin{array}{l}\text { 44-year-old, } \\
\text { male }\end{array}$ & Sneezing & $\begin{array}{l}\text { Supraglottic oedema. Normal } \\
\text { vocal cord movements }\end{array}$ & N/A & $\begin{array}{l}\text { Observation: anterior } \\
\text { neck strapping, liquid } \\
\text { diet for three days, voice } \\
\text { rest }\end{array}$ \\
\hline $\begin{array}{l}\text { Martinez et } \\
\text { al. (2007) [7] }\end{array}$ & $\begin{array}{l}\text { 29-year-old, } \\
\text { male }\end{array}$ & Sneezing & $\begin{array}{l}\text { Right vocal cord oedema. Right } \\
\text { false vocal cord haematoma. } \\
\text { Normal vocal cord movements }\end{array}$ & $\begin{array}{l}\text { Anterior thyroid cartilage } \\
\text { fracture. Non-displaced }\end{array}$ & Observation: voice rest \\
\hline $\begin{array}{l}\text { Alexander } \\
\text { and Toynton } \\
\text { (2012) [6] }\end{array}$ & $\begin{array}{l}\text { 41-year-old, } \\
\text { male }\end{array}$ & Coughing & $\begin{array}{l}\text { Left vocal cord haematoma. } \\
\text { Normal vocal cord movements }\end{array}$ & $\begin{array}{l}\text { Midline thyroid cartilage } \\
\text { fracture. Slight } \\
\text { displacement }\end{array}$ & $\begin{array}{l}\text { Observation: nil by } \\
\text { mouth for three days, } \\
\text { voice rest }\end{array}$ \\
\hline $\begin{array}{l}\text { Fenig et al. } \\
\text { (2013) [5] }\end{array}$ & $\begin{array}{l}\text { 47-year-old, } \\
\text { male }\end{array}$ & Coughing & $\begin{array}{l}\text { Right aryepiglottic fold and } \\
\text { arytenoid cartilage oedema. } \\
\text { Normal vocal cord movements }\end{array}$ & $\begin{array}{l}\text { Anterior thyroid cartilage } \\
\text { fracture. Mildly } \\
\text { displaced. Adjacent } \\
\text { phlegmon }\end{array}$ & $\begin{array}{l}\text { Observation: voice rest, } \\
\text { oral antibiotics }\end{array}$ \\
\hline $\begin{array}{l}\text { Santamaria } \\
\text { et al. (2017) } \\
\text { [3] }\end{array}$ & $\begin{array}{l}\text { 36-year-old, } \\
\text { male }\end{array}$ & Sneezing & $\begin{array}{l}\text { Left vocal cord haematoma. } \\
\text { Normal vocal cord movements }\end{array}$ & $\begin{array}{l}\text { Left parasagittal thyroid } \\
\text { cartilage fracture. Non- } \\
\text { displaced }\end{array}$ & $\begin{array}{l}\text { Observation: voice rest, } \\
\text { oral corticosteroids }\end{array}$ \\
\hline $\begin{array}{l}\text { Santamaria } \\
\text { et al. (2017) } \\
\text { [3] }\end{array}$ & $\begin{array}{l}\text { 32-year-old, } \\
\text { male }\end{array}$ & $\begin{array}{l}\text { Swallowing } \\
\text { while } \\
\text { bending over }\end{array}$ & $\begin{array}{l}\text { Supraglottic oedema. Normal } \\
\text { vocal cord movements }\end{array}$ & $\begin{array}{l}\text { Left parasagittal thyroid } \\
\text { cartilage fracture. Non- } \\
\text { displaced }\end{array}$ & $\begin{array}{l}\text { Observation: voice rest, } \\
\text { non-steroidal anti- } \\
\text { inflammatory drugs }\end{array}$ \\
\hline $\begin{array}{l}\text { Matrka and } \\
\text { Li (2018) [4] }\end{array}$ & $\begin{array}{l}\text { 35-year-old, } \\
\text { male }\end{array}$ & Sneezing & $\begin{array}{l}\text { Right vocal cord oedema. } \\
\text { Normal vocal cord movements }\end{array}$ & $\begin{array}{l}\text { Right parasagittal } \\
\text { thyroid cartilage } \\
\text { fracture. Non-displaced }\end{array}$ & Observation: voice rest \\
\hline
\end{tabular}

TABLE 1: A summary of all previously reported cases of non-traumatic laryngeal fracture.

While four cases described a fracture occurring after sneezing [2-4,7], and two reported it after coughing $[5,6]$, there has only been one that mentioned a fracture occurring after swallowing [3]. In that case, symptoms started abruptly after the patient swallowed while bending over during dinner. The aetiology of non-traumatic laryngeal fracture is unknown. Pathological fracture due to an inflammatory condition or a neoplastic process should be considered [4]. However, in this case and all those reported previously, no underlying disease was found. One theory suggests the possible presence of a congenital anomaly or dehiscence of the cartilage, creating an area of weakness that is predisposed to fracture $[2,6]$. All previously reported cases occurred in males aged 29-47 years. They shared a common history of the patient feeling a crack in their neck abruptly after the precipitating event, before acutely developing dysphonia, dysphagia and odynophagia. All reported tenderness and swelling over the thyroid cartilage on examination. FNE findings included unilateral vocal cord oedema $[4,5,7]$ and false cord haematoma $[2,3,7]$. Vocal cord movement was intact in all cases. Common findings on CT were of a non-displaced [3,4,6,7], or mildly displaced [5], anterior parasagittal laryngeal fracture. All patients were managed conservatively with observation and vocal rest, and made a full recovery.

This case gives support to there being a typical pattern to the presentation of this injury. Although all previous cases presented directly to the emergency department where same-day imaging allowed for a prompt diagnosis, this case highlights how this pathology may also be seen initially in primary care. In this setting, imaging and specialist review is not as readily available and thus can make diagnosis a challenge. This is the first reported case of a non-traumatic fracture being diagnosed upon re-presentation, where symptoms were rapidly evolving due to a large anterior neck swelling causing fracture displacement. While non-traumatic fractures appear to be frequently non-displaced and have previously all been amenable to conservative management, this case illustrates how concurrent adjacent infection and swelling can cause significant fracture displacement that requires operative intervention.

\section{Conclusions}

Non-traumatic laryngeal fractures are rare; this case illustrates how they can pose a diagnostic challenge. It is the first to describe the presentation and surgical management of a case with fracture displacement due to localised infection. A typical history of a perceived sudden crack in the neck combined with the symptoms of dysphonia, dysphagia or odynophagia should raise suspicion and prompt further investigation for this 


\section{Cureus}

pathology, even in the absence of a direct traumatic mechanism.

\section{Additional Information}

\section{Disclosures}

Human subjects: Consent was obtained by all participants in this study. Conflicts of interest: In compliance with the ICMJE uniform disclosure form, all authors declare the following: Payment/services info: All authors have declared that no financial support was received from any organization for the submitted work. Financial relationships: All authors have declared that they have no financial relationships at present or within the previous three years with any organizations that might have an interest in the submitted work. Other relationships: All authors have declared that there are no other relationships or activities that could appear to have influenced the submitted work.

\section{References}

1. Jalisi S, Zoccoli M: Management of laryngeal fractures: a 10-year experience. J Voice. 2011, 25:473-479. 10.1016/j.jvoice.2009.12.008

2. Quinlan P: Fracture of thyroid cartilage during a sneezing attack. Br Med J. 1950, 1:1052. 10.1136/bmj.1.4661.1052

3. Santamaria A, Alarcon R, Sepulveda I, Fredes F: Nontraumatic laryngeal fractures: report of two cases and review of the literature. Case Rep Otolaryngol. 2017, 2017:2153521. 10.1155/2017/2153521

4. Matrka L, Li M: Laryngeal fracture following violent sneeze: management and biochemical analysis . ОTO Open. 2018, 2:1-2. 10.1177/2473974X18757741

5. Fenig M, Strasberg S, Cohen J, Almadi R, Gold M: Laryngeal fracture after coughing. Am J Emerg Med. 2013, 31:1421.e1-1421.e3. 10.1016/j.ajem.2013.05.013

6. Alexander V, Toynton S: Spontaneous fracture of the larynx after coughing . Otolaryngol Head Neck Surg. 2012, 147:801-802. 10.1177/0194599812445744

7. Martinez A, Juara A, Moya J: Fracture of thyroid cartilage after a sneezing episode. (Article in Spanish) . Acta Otorrinolaringol Esp. 2007, 58:73-74. 10.1016/s0001-6519(07)74884-7 